\title{
Assessment of the response to chemotherapy in gestational trophoblastic neoplasia with vaginal metastases
}

\author{
Fatemeh Ghaemmaghami $\cdot$ Shohreh Behroozi $\cdot$ Azamolsadat Mousavi \\ Tahereh Ashrafgangooei - Mitra Modares Gilani · Nadereh Behtash · \\ Zinat Ghanbari
}

Published online: 22 October 2008

(C) Springer-Verlag 2008

Erratum to: Arch Gynecol Obstet (2008) 278:315-318

DOI 10.1007/s00404-008-0588-5

Unfortunately, first names and last names of the authors were interchanged in the online and printed version of this article. Instead of "Ghaemmaghami Fatemeh, Behroozi Shohreh, Mousavi Azamolsadat, Ashrafgangooei Tahereh, Modares Gilani Mitra, Behtash Nadereh, Ghanbari Zinat", they should read as "Fatemeh Ghaemmaghami, Shohreh Behroozi, Azamolsadat Mousavi, Tahereh Ashrafgangooei, Mitra Modares Gilani, Nadereh Behtash, Zinat Ghanbari”.

The online version of the original article can be found under doi: 10.1007/s00404-008-0588-5.

F. Ghaemmaghami · A. Mousavi · M. Modares Gilani · N. Behtash Gynecology Oncology Department,

Tehran University of Medical Sciences, Tehran, Iran

S. Behroozi

Gynecology and Obstetrics Resident,

Tehran University of Medical Sciences, Tehran, Iran

T. Ashrafgangooei

Gynecology Oncology Department,

Kerman University of Medical Sciences, Tehran, Iran

e-mail: tganjoei@yahoo.com

Z. Ghanbari

Gynecology and Obstetrics Department,

Tehran University of Medical Sciences, Tehran, Iran

F. Ghaemmaghami ( $\square)$

Gynecology Oncology Department, Vali-e-Asr Hospital, Imam Khomeini's Hospital Complex, Keshavarz Blvd,

Tehran, Iran

e-mail: ftghaemmagh@yahoo.com; valrec2@yahoo.com 